\title{
HUBUNGAN PENGETAHUAN DENGAN PERILAKU PENGGUNAAN GREEN PACKAGING DI MASYARAKAT DKI JAKARTA
}

\section{THE RELATIONSHIP OF KNOWLEDGE WITH BEHAVIOR IN THE USE OF GREEN PACKAGING IN DKI JAKARTA}

\author{
Anisa Nuraini Priambudi*, Yosini Deliana \\ Program Studi Agribisnis, Fakultas Pertanian, Universitas Padjadjaran \\ Jl. Raya Bandung-Sumedang Km. 21 \\ *E-mail : anisan078@gmail.com \\ (Diterima 16-08-2020; Disetujui 01-11-2020)
}

\begin{abstract}
ABSTRAK
DKI Jakarta merupakan kota metropolitan yang terkenal sebagai langganan banjir dan menduduki peringkat 1 sebagai wilayah dengan sampah terbanyak di Indonesia. Berbagai upaya telah dilakukan pemerintah untuk mengurangi penggunaan plastik sebagai salah satu sampah yang sulit terurai, baik berupa himbauan hingga peraturan. Penelitian ini bertujuan untuk mengetahui hubungan pengetahuan dengan perilaku penggunaan green packaging pada masyarakat DKI Jakarta. Penelitian ini termasuk jenis penelitian kuantitatif dengan menggunakan metode survei dan analisis korelasi pearson. Hasil analisis menunjukkan bahwa semakin tinggi tingkat pengetahuan masyarakat tentang green packaging akan berpengaruh baik terhadap perilaku penggunaan green packaging. Faktor dominan yang menjadi pertimbangan masyarakat dalam mengenal dan menggunakan green packaging adalah peduli lingkungan, media sosial dan lingkungan sosial sekitar. Masyarakat sudah cukup banyak yang mengetahui Peraturan Gurbenur Provinsi DKI Jakarta Nomor 142 Tahun 2019 tentang kewajiban penggunaan kantong belanja ramah lingkungan pada pusat perbelanjaan, toko swalayan dan pasar rakyat. Selain itu, juga masyarakat bersedia untuk mulai beralih ke green packaging sedikit demi sedikit seperti membawa kantong belanja sendiri, botol minum dan tempat makan sendiri, serta mengedukasi orang-orang di sekitarnya untuk mau melakukan hal serupa.
\end{abstract}

Kata kunci : Pengetahuan, Perilaku, Analisis Korelasi Pearson, Green Packaging

\section{ABSTRACT}

DKI Jakarta is a metropolitan city which is well-known as a flood subscriber and ranks number 1 as the region with the most waste in Indonesia. Various attempts have been done by the government to reduce the use of plastic as one of the waste that is difficult to decompose, both in the form of appeals to regulations. This study aims to determine the relationship of knowledge with the use of green packaging behavior in the people of DKI Jakarta. This research is a quantitative research using survey method and Pearson correlation analysis. The analysis shows that the higher level of public knowledge about green packaging will have a good effect on the behavior of using green packaging. The dominant factor that is considered by the public in recognizing and using green packaging is environmental care, social media and the surrounding social environment. Many people have already know about the Regulations of the Governor of DKI Jakarta Number 142 Year 2019 regarding the obligation to use environmentally friendly shopping bags at shopping centers, supermarkets and people's markets. In addition, the community is willing to start switching to green packaging little by little, such as carrying their own shopping bags, drinking bottles and lunch boxes, and educating people around them to do the same.

Keywords: Knowledge, Behavior, Pearson Correlation Analysis, Green Packaging 


\section{PENDAHULUAN}

Saat ini sampah dan limbah menjadi masalah utama di seluruh dunia, salah satunya Indonesia. Menurut UU No. 18 Tahun 2008, pertambahan jumlah penduduk, ekonomi, dan pola konsumsi yang berubah dari waktu ke waktu merupakan beberapa penyebab meningkatnya jumlah sampah setiap tahunnya. Jenis sampah yang sulit didaur ulang dan dikurangi pemakaiannya adalah sampah plastik. Sampah plastik membutuhkan waktu yang sangat lama untuk terurai sempurna. Bahan plastik konvesional butuh waktu 500-1.000 tahun untuk terurai dalam tanah (Ridwan et al, 2018). Berdasarkan data penelitian yang dilakukan oleh Jambeck (2015), Indonesia menduduki peringkat kedua di dunia sebagai negara penghasil sampah plastik terbanyak ke laut setelah China.

Gaya hidup masyarakat yang berubah membuat pola konsumsi juga berubah, di mana masyarakat lebih memilih hal-hal yang lebih mudah dan praktis. Salah satunya adalah penggunaan bahan plastik pada alat makan, botol minum, kantong pembungkus, dan lainlain. Perilaku ini tidak hanya dimotivasi oleh kebutuhan pribadi konsumen, tetapi juga oleh pertimbangan konsekuensi lingkungan dari pilihan konsumsi
(Deliana et al, 2017). Penggunaan plastik tersebut telah mendominasi kemasan di dunia terutama pada industri makanan, menggantikan kemasan kaleng dan gelas. Padahal penggunaan plastik yang berlebihan terutama sebagai pembungkus makanan akan menimbulkan berbagai macam gangguan kesehatan pada manusia (Arifin, 2017). Selain itu, juga akan menimbulkan banyak masalah secara langsung maupun tidak langsung dari sampah atau limbah seperti polusi udara, air, banjir, dan masalah lainnya (Keman, 2005).

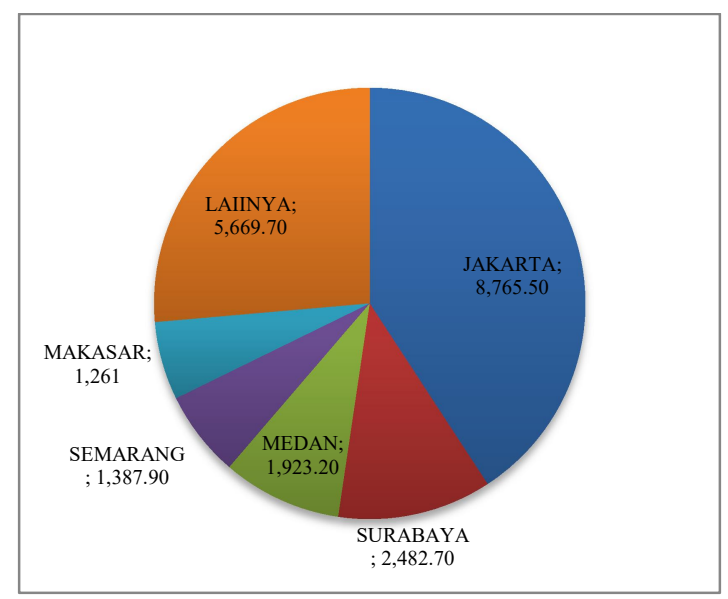

Gambar 1. Jumlah Sampah Beberapa Kota di Indonesia Tahun 2018

Sumber: Statistik Lingkungan Hidup Indonesia 2018

DKI Jakarta adalah contoh kota besar di Indonesia yang menghadapi banyak kendala dalam pengelolaan limbah (Mahyudin, 2017). Berdasarkan Gambar 1 terlihat bahwa DKI Jakarta menduduki peringkat 1 sebagai wilayah dengan sampah terbanyak di Indonesia 
yaitu sekitar 8.765 ton per harinya. Banyaknya jumlah penduduk yang tinggal di wilayah DKI Jakarta mempengaruhi bertambahnya jumlah sampah dan limbah, sehingga tidak heran jika sering terjadi bencana banjir saat musim hujan tiba. Belum lagi penduduk kota Jakarta merupakan penduduk perkotaan yang mudah mengadopsi trentren baru dari luar negeri dan mudah menerima perubahan. Semakin mengarah ke daerah perkotaan maka perubahan pola konsumsi semakin nyata dan membuat naiknya jumlah timbunan sampah (Kahfi, 2017).

Semakin banyaknya dampak yang terjadi akibat peningkatan sampah setiap harinya, membuat kesadaran masyarakat akan pentingnya kelestarian lingkungan juga semakin meningkat. Tren mengurangi sampah plastik juga mulai menyebar luas tertama pada social media. Belum lagi pada saat ini banyak social media influencer yang menyatakan bahwa dirinya sudah mulai mengurangi penggunaan plastik.

Selain masyarakat, para pelaku usaha juga dituntut untuk melakukan perubahan pola pendekatan ke arah aktivitas bisnis yang berwawasan lingkungan atau green marketing (Muslim dan Indriani, 2014). Fakta ini didukung dengan mulai banyaknya aktivitas peduli lingkungan dan demo peduli lingkungan seperti penanaman 1000 pohon, say no to plastic, dan sebagainya. Green Marketing adalah suatu konsep kegiatan pemasaran produk yang memperhatikan dampak-dampak yang timbul pada lingkungan alam sekitar.

Salah satu yang penting dalam menjalankan green marketing adalah dengan memperhatikan kemasan yang harus ramah lingkungan atau biasa disebut green packaging. Green Packaging merupakan konsep kemasan yang terbuat dari bahan yang tidak membahayakan lingkungan dan dapat didaur ulang. Green Packaging biasanya terbuat dari bahan pati dan Poly Lactic Acid (PLA) (Coniwanti dan Alfira, 2015). Pati diperoleh dari bahan nabati yang banyak mengandung karbohidrat seperti singkong, ubi, jagung, dan serealia.

Green Packaging yang bersifat recycling dan reusing diharapkan dapat mengurangi penggunaan plastik dalam kegiatan sehari-hari. Namun dalam penerapan green packaging ada beberapa faktor yang mempengaruhi keputusan konsumen di antaranya adalah pengetahuan dan perilaku. Faktanya untuk menerapkan green packaging pada 


\section{HUBUNGAN PENGETAHUAN DENGAN PERILAKU PENGGUNAAN \\ GREEN PACKAGING DI MASYARAKAT DKI JAKARTA \\ Anisa Nuraini Priambudi, Yosini Deliana}

suatu produk, pelaku usaha harus mengeluarkan biaya lebih. Selain itu tidak sedikit pula konsumen yang memilih produk bukan karena produk tersebut ramah lingkungan dari segi isi atau packaging-nya namun faktor utama yang dipertimbangkan oleh konsumen biasanya adalah harga dan kebutuhannya untuk kehidupan sehari-hari. Hal ini didukung oleh hasil penelitian yang dilakukan Rokka dan Uusitalo (2008) bahwa konsumen yang menaruh perhatian pada produk ramah lingkungan juga mempertimbangkan dari segi harga. Harga produk ramah lingkungan jauh lebih mahal daripada produk non hijau; hanya pasar tertentu yang dapat menyediakan produk hijau seperti barang organic (Deliana dan Rum, 2019).

Semakin tingginya tingkat pengetahuan masyarakat terhadap kerusakan lingkungan yang dihasilkan oleh sampah plastik dan kesadaran akan produk ramah lingkungan diharapkan mampu mempengaruhi perilaku masyarakat itu sendiri. Hal ini didukung oleh penelitian Ferguson dan Bargh (2004) yang menyatakan bahwa perilaku merupakan respon dari adanya bentukbentuk pengetahuan sosial dan dipresentasikan secara otomatis ketika persepsi muncul akibat respon dari pemahaman stimulus sosial. Maka pengetahuan masyarakat menjadi penting untuk dikaji agar dapat mengetahui apakah tingkat pengetahuan masyarakat terhadap green packaging berpengaruh positif terhadap perilakunya atau sebaliknya.

\section{METODE PENELITIAN}

Penelitian dilakukan menggunakan pendekatan kuantitatif dengan metode survei. Objek dalam penelitian ini adalah hubungan pengetahuan dengan perilaku penggunaan green packaging pada masyarakat DKI Jakarta. Variabel yang diteliti adalah pengetahuan masyarakat tentang bahaya sampah plastik dan manfaat green packaging, serta perilaku masyarakat dalam rangka mengurangi sampah plastik.

Teknik pengambilan sampel yang digunakan adalah probability random sampling, yaitu teknik pengambilan sampel yang memberikan peluang yang sama kepada setiap anggota populasi untuk menjadi sampel (Sugiyono, 2015). Teknik pengambilan sampel ini dilakukan dengan menyebar sejumlah kuesioner dengan secara acak berdasarkan kesediaan responden untuk menerima dan mengisi kuesioner secara lengkap. Alasan pemilihan teknik 
pengambilan sampel ini adalah untuk mempermudah pengambilan sampel.

Data yang digunakan terdiri atas data primer dan sekunder. Data primer merupakan data yang langsung didapat ketika penelitian, sedangkan data sekunder merupakan data pendukung dari berbagai sumber buku, jurnal, maupun lainnya. Teknik pengumpulan data dalam penelitian berupa observasi, wawancara, penyebaran kuesioner, dan dokumentasi.

Analisis data yang digunakan adalah tabulasi silang dan uji korelasi pearson. Tabulasi silang atau crosstab dilakukan untuk menjabarkan tentang karakteristik responden sedangkan uji korelasi pearson digunakan untuk mengetahui hubungan antara pengetahuan dengan perilaku penggunaan green packaging pada masyarakat DKI Jakarta.

\section{HASIL DAN PEMBAHASAN}

Tabel 1 menunjukkan bahwa responden didominasi oleh masyarakat dengan jenis kelamin perempuan sebanyak $68 \%$ dan sisanya adalah lakilaki sebanyak 32\%. Apabila dilihat dari jenis kelamin sebagian besar responden belum memiliki pengetahuan yang baik terhadap green packaging; artinya baik laki-laki maupun perempuan belum mengetahui manfaat penggunaan green packaging dengan benar.

\begin{tabular}{|c|c|c|c|c|c|c|}
\hline Tabel & 1. & \multicolumn{3}{|c|}{ Karakteristik } & \multicolumn{2}{|c|}{$\begin{array}{l}\text { Responden } \\
\text { Kelamin }\end{array}$} \\
\hline \multirow{3}{*}{$\begin{array}{l}\text { Jenis } \\
\text { Kelamin }\end{array}$} & \multirow{2}{*}{\multicolumn{2}{|c|}{$\begin{array}{l}\text { Tingkat } \\
\text { Pengetahuan }\end{array}$}} & \multirow{3}{*}{ Total } & \multirow{2}{*}{\multicolumn{2}{|c|}{$\begin{array}{c}\text { Perilaku } \\
\text { Penggunaan } \\
\text { Green } \\
\text { Packaging }\end{array}$}} & \multirow{3}{*}{ Total } \\
\hline & & & & & & \\
\hline & $\begin{array}{c}\text { Kurang } \\
\text { Baik }\end{array}$ & Baik & & $\begin{array}{c}\text { Kurang } \\
\text { Baik }\end{array}$ & Baik & \\
\hline Perempuan & 50 & 18 & 68 & 42 & 26 & 68 \\
\hline Laki-Laki & 22 & 10 & 32 & 17 & 15 & 32 \\
\hline Total & 72 & 28 & 100 & 59 & 41 & 100 \\
\hline
\end{tabular}

Sumber: Analisis Data Primer (2020)

Aspek pengetahuan sejalan dengan perilaku yang ditimbulkan di mana sebagian besar baik responden laki-laki maupun perempuan memiliki perilaku kurang baik dalam penggunaan green packaging atau dengan kata lain belum menggunakan green packaging dalam kehidupan sehari-hari.

\begin{tabular}{|c|c|c|c|c|c|c|}
\hline Tabel & \multicolumn{6}{|c|}{$\begin{array}{l}\text { Karakteristik } \\
\text { Berdasarkan Usia }\end{array}$} \\
\hline \multirow[t]{2}{*}{$\begin{array}{l}\text { Usia } \\
\text { (tahun) }\end{array}$} & \multicolumn{2}{|c|}{$\begin{array}{c}\text { Tingkat } \\
\text { Pengetahuan }\end{array}$} & \multirow[t]{2}{*}{ Total } & \multicolumn{2}{|c|}{$\begin{array}{c}\text { Perilaku } \\
\text { Penggunaan } \\
\text { Green } \\
\text { Packaging }\end{array}$} & \multirow[t]{2}{*}{ Total } \\
\hline & $\begin{array}{c}\text { Kurang } \\
\text { Baik }\end{array}$ & Baik & & $\begin{array}{c}\text { Kurang } \\
\text { Baik }\end{array}$ & Baik & \\
\hline$<18$ & 1 & 4 & 5 & 2 & 3 & 5 \\
\hline $18-28$ & 30 & 11 & 41 & 21 & 20 & 41 \\
\hline $29-39$ & 33 & 8 & 41 & 27 & 14 & 41 \\
\hline$>40$ & 8 & 5 & 13 & 9 & 4 & 13 \\
\hline Total & 72 & 28 & 100 & 59 & 41 & 100 \\
\hline
\end{tabular}

Sumber: Analisis Data Primer (2020)

Berdasarkan Tabel 2 jumlah responden terbanyak yaitu masyarakat dengan usia $<18$ tahun sebanyak 5\%, usia kisaran 18-28 tahun sebanyak 41\%. Selanjutnya usia 29-39 tahun sebanyak $41 \%$, dan usia $>40$ tahun sebanyak $13 \%$.

Berdasarkan kelompok umur, responden mayoritas belum memiliki pengetahuan yang baik tentang bahaya 


\section{HUBUNGAN PENGETAHUAN DENGAN PERILAKU PENGGUNAAN \\ GREEN PACKAGING DI MASYARAKAT DKI JAKARTA \\ Anisa Nuraini Priambudi, Yosini Deliana}

sampah plastik dan manfaat green packaging, hanya masyarakat yang berusia kurang dari 18 tahun yang mulai menyadari tentang green packaging. Sedangkan usia 18 tahun ke atas mayoritas kurang peduli terhadap informasi green packaging.

Apabila dari aspek perilaku, mayoritas responden dari beragam usia masih termasuk kategori kurang baik atau belum menggunakan green packaging untuk mengurangi penggunaan plastik. Namun diketahui bahwa masyarakat pada kategori usia kurang dari 18 tahun dan rentang usia 18-28 tahun sudah cukup banyak yang mau menggunakan green packaging dalam kehidupan sehari-hari.

\begin{tabular}{|c|c|c|c|c|c|c|}
\hline \multirow{3}{*}{ Pendidikan } & \multicolumn{4}{|c|}{$\begin{array}{l}\text { Karakteristik } \\
\text { Berdasarkan } \\
\text { Pendidikan }\end{array}$} & \multicolumn{2}{|c|}{$\begin{array}{r}\text { Responden } \\
\text { Tingkat }\end{array}$} \\
\hline & \multicolumn{2}{|c|}{$\begin{array}{c}\text { Tingkat } \\
\text { Pengetahuan }\end{array}$} & \multirow[t]{2}{*}{ Total } & \multicolumn{2}{|c|}{$\begin{array}{c}\text { Perilaku } \\
\text { Penggunaan } \\
\text { Green } \\
\text { Packaging }\end{array}$} & \multirow[t]{2}{*}{ Total } \\
\hline & $\begin{array}{c}\text { Kurang } \\
\text { Baik }\end{array}$ & Baik & & $\begin{array}{c}\text { Kurang } \\
\text { Baik }\end{array}$ & Baik & \\
\hline SD & 0 & 1 & 1 & 0 & 1 & 1 \\
\hline SMP & 1 & 2 & 3 & 1 & 2 & 3 \\
\hline SMA & 12 & 6 & 18 & 9 & 9 & 18 \\
\hline $\mathrm{D} 3 / \mathrm{S} 1 / \mathrm{S} 2$ & 59 & 19 & 78 & 49 & 29 & 78 \\
\hline Total & 72 & 28 & 100 & 59 & 41 & 100 \\
\hline
\end{tabular}

Sumber: Analisis Data Primer (2020)

Berdasarkan Tabel 3 diketahui bahwa mayoritas responden yang berpendidikan akhir D3/S1/S2/S3 sebesar $78 \%$ dan sisanya adalah berpendidikan SMA sebanyak 18\%, SMP sebanyak 3\% dan berpendidikan akhir di tingkat SD sebanyak $1 \%$ dari total responden.
Dari tabel dapat diketahui bahwa semakin tinggi tingkat pendidikan tidak menjamin semakin baik akan pengetahuannya, di mana pada tabel tersebut jumlah masyarakat semakin banyak yang memiliki tingkat pengetahuan kurang baik tentang green packaging seiring dengan semakin tingginya tingkat pendidikan.

Hal tersebut sejalan dengan perilaku, di mana tabel menunjukkan bahwa responden mayoritas masih berperilaku kurang baik atau belum menggunakan green packaging untuk mengurangi penggunaan plastik dalam kehidupan sehari-hari, khususnya mereka yang berpendidikan di tingkat D3/S1/S2 . Sedangkan untuk responden masyarakat dengan tingkat pendidikan yang lebih rendah sudah mulai mau menggunakan green packaging.

\begin{tabular}{|c|c|c|c|c|c|c|}
\hline Tabel 4 & \multicolumn{3}{|c|}{ Karakteristik } & \multicolumn{2}{|c|}{$\begin{array}{l}\text { Responden } \\
\text { eriaan }\end{array}$} & \\
\hline \multirow[t]{2}{*}{ Pekerjaan } & \multicolumn{2}{|c|}{$\begin{array}{c}\text { Tingkat } \\
\text { Pengetahuan }\end{array}$} & \multirow[t]{2}{*}{ Total } & \multicolumn{2}{|c|}{$\begin{array}{l}\text { Perilaku } \\
\text { Penggunaan } \\
\text { Green } \\
\text { Packaging }\end{array}$} & \multirow[t]{2}{*}{ Total } \\
\hline & $\begin{array}{c}\text { Kurang } \\
\text { Baik }\end{array}$ & Baik & & $\begin{array}{c}\text { Kurang } \\
\text { Baik }\end{array}$ & Baik & \\
\hline Pelajar/Mahasiswa & 15 & 9 & 24 & 14 & 10 & 24 \\
\hline PNS & 4 & 4 & 8 & 5 & 3 & 8 \\
\hline Pegawai Swasta & 24 & 8 & 32 & 19 & 13 & 32 \\
\hline Wiraswasta & 8 & 3 & 11 & 7 & 4 & 11 \\
\hline Lainnya & 21 & 4 & 25 & 14 & 11 & 25 \\
\hline Total & 72 & 28 & 100 & 59 & 41 & 100 \\
\hline
\end{tabular}

Sumber: Analisis Data Primer (2020)

$$
\text { Berdasarkan Tabel } 4 \text { dapat }
$$
disimpulkan bahwa responden masyarakat paling banyak berprofesi sebagai pegawai swasta yaitu sebanyak 
$32 \%$, diikuti dengan ibu rumah tangga atau pensiunan sebanyak $25 \%$. Kemudian $24 \%$ masyarakat berprofesi sebagai pelajar/mahasiswa, $\quad 11 \% \quad$ sebagai wiraswasta dan sisanya $8 \%$ bekerja sebagai pegawai negeri sipil.

Dari Tabel 4 juga dapat diketahui bahwa berdasarkan berbagai jenis pekerjaan, responden masyarakat banyak yang belum memiliki pengetahuan baik tentang bahaya sampah plastik dan manfaat green packaging. Hal tersebut sejalan dengan perilaku yang ditimbulkan di mana mayoritas belum menggunakan green packaging dalam rangka mengurangi penggunaan plastik dalam kehidupan sehari-hari.

\begin{tabular}{|c|c|c|c|c|c|c|}
\hline \multirow{3}{*}{ Pendapatan } & \multicolumn{6}{|c|}{$\begin{array}{l}\text { Karakteristik } \\
\text { Berdasarkan } \mathbf{P}\end{array}$} \\
\hline & \multicolumn{2}{|c|}{$\begin{array}{c}\text { Tingkat } \\
\text { Pengetahuan }\end{array}$} & \multirow[t]{2}{*}{ Total } & \multicolumn{2}{|c|}{$\begin{array}{c}\text { Perilaku } \\
\text { Penggunaan } \\
\text { Green } \\
\text { Packaging } \\
\end{array}$} & \multirow[t]{2}{*}{ Total } \\
\hline & $\begin{array}{c}\text { Kurang } \\
\text { Baik }\end{array}$ & Baik & & $\begin{array}{c}\text { Kurang } \\
\text { Baik }\end{array}$ & Baik & \\
\hline$<1$ juta & 9 & 8 & 17 & 8 & 9 & 17 \\
\hline $1-3$ juta & 17 & 4 & 21 & 14 & 7 & 21 \\
\hline$>3$ juta & 46 & 16 & 62 & 37 & 25 & 62 \\
\hline Total & 72 & 28 & 100 & 59 & 41 & 100 \\
\hline
\end{tabular}

Sumber: Analisis Data Primer (2020)

Tabel 5 menunjukkan bahwa lebih dari setengahnya, masyarakat yang menjadi responden berpendapatan ratarata di atas $\mathrm{Rp} 3.000 .000$ per bulan sebanyak $62 \%$. Kemudian sebanyak $21 \%$ berpendapatan antara $\mathrm{Rp} 1.000 .000-\mathrm{Rp}$ 3.000 .000 , dan sisanya $17 \%$ masyarakat berpendapatan di bawah $\mathrm{Rp} 1.000 .000$ per bulan.
Apabila dilihat dari sisi pendapatan, semakin tinggi pendapatan tidak berbanding lurus terhadap pengetahuan tentang penggunaan green packaging. Sebagian besar masyarakat yang memiliki pendapatan tinggi di atas $\mathrm{Rp}$ 3.000.000 cenderung memiliki pengetahuan yang kurang baik terhadap green packaging.

Berdasarkan kategori pendapatan, perilaku masyarakat juga masih kurang baik atau belum menggunakan green packaging. Artinya masyarakat DKI Jakarta belum menjadikan besarnya pendapatan sebagai acuan untuk menggunakan green packaging dalam kehidupan sehari-hari.

Tabel 6. Hasil Uji Korelasi Pearson

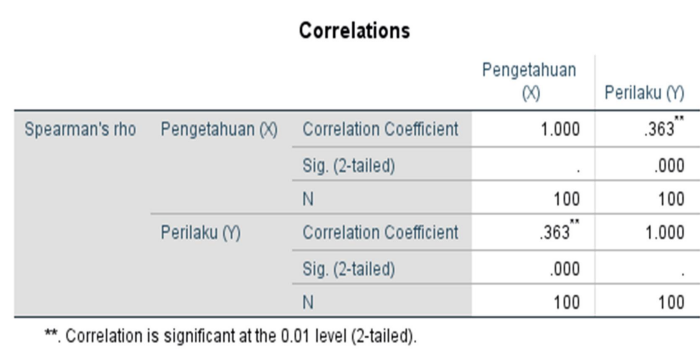

Sumber: Analisis Data Primer (2020)

Nilai korelasi pearson (r-hitung) dengan taraf signifikansi $5 \%$ untuk hubungan pengetahuan dan perilaku penggunaan green packaging adalah sebesar 0.363 di mana jika dibandingkan dengan nilai r-tabel yang bernilai sebesar 0.1966 , nilai r-hitung $>$ r-tabel dan nilai signifikansi antara pengetahuan dengan 


\section{HUBUNGAN PENGETAHUAN DENGAN PERILAKU PENGGUNAAN \\ GREEN PACKAGING DI MASYARAKAT DKI JAKARTA \\ Anisa Nuraini Priambudi, Yosini Deliana}

perilaku adalah sebesar 0.000 di mana nilai tersebut lebih kecil daripada taraf signifikansi yaitu $5 \%$ sehingga $\mathrm{H}_{0}$ ditolak, sehingga $\mathrm{H}_{0}$ ditolak yang berarti terdapat hubungan yang signifikan antara pengetahuan dengan perilaku atau semakin baik pengetahuan tentang green packaging maka semakin baik pula perilakunya. Nilai korelasi spearman (rhitung) dalam analisis ini memiliki hubungan yang lemah dan bernilai positif yang berarti semakin meningkatnya pengetahuan maka membuat perilaku ikut meningkat.

Hasil tersebut sejelan dengan penelitian yang dilakukan oleh Osman et al (2014) yang menyatakan bahwa pengetahuan terhadap lingkungan berpengaruh signifikan terhadap perilaku masyarakat terhadap lingkungan itu sendiri. Selanjutnya penelitian yang dilakukan oleh Utami dan Prastika (2015) tentang hubungan pengetahuan tentang dismenore dengan perilaku pencegahannya juga menyatakan bahwa terdapat hubungan yang signifikan antara tingkat pengetahuan tentang dismenore dengan perilaku pencegahan dismenore.

Berbeda dengan penelitian sejenis yang telah dilakukan sebelumnya oleh Sumbung (2012) yang menjelaskan bahwa tidak terdapat hubungan antara pengetahuan dengan perilaku responden dalam mengurangi penggunaan kantong plastik di Manado. Penelitian yang dilakukan oleh Asti dan Novita (2017) tentang pengetahuan, sikap, dan pendidikan dengan perilaku pengelolaan sampah di Kelurahan Bener, Kecamatan Tegalrejo, Yogyakarta juga menyatakan bahwa tidak terdapat hubungan antara tingkat pengetahuan dengan perilaku pengelolaan sampah di Yogyakarta.

Hubungan antara pengetahuan terhadap perilaku penggunaan green packaging pada masyarakat di DKI Jakarta memang signifikan, namun dalam hal ini perlu diperhatikan dan ditingkatkan. Berdasarkan data di atas, masyarakat masih banyak yang belum mengetahui tentang green packaging dan itu berbanding lurus dengan perilaku yang ditimbulkannya, di mana dikarenakan kurang peduli terhadap informasi green packaging akhirnya masyarakat juga tidak menggunakan green packaging.

Hal tersebut dapat disebabkan oleh beberapa hal, di antaranya masyarakat masih banyak memilih segala sesuatu yang praktis. Macetnya wilayah DKI Jakarta dan kecanggihan teknologi yang ada membuat banyak masyarakat memilih hal-hal yang praktis seperti 
memesan makanan melalui sistem delivery online yang pada akhirnya menyumbang sampah. Selain itu, masih belum terbiasanya masyarakat membawa kantong belanja sendiri ketika berbelanja dan masih ada saja yang merasa malu membuat masyarakat tersebut lebih memilih untuk membayar kantong plastik yang hanya dihargai Rp 200. Masyarakat mengakui bahwa sampah plastik sudah banyak dan menimbulkan berbagai dampak di mana yang paling sering terjadi adalah banjir, namun untuk beralih ke green packaging dianggap masih sulit.

Berdasarkan hasil lapangan, faktor yang mempengaruhi masyarakat DKI Jakarta dalam menggunakan green packaging adalah faktor peduli lingkungan, lingkungan sosial dan social media. Hal tersebut sesuai dengan hasil lapangan yang menunjukkan bahwa masyarakat ingin berusaha beralih ke green packaging karena kondisi lingkungan yang saat ini terus memburuk khususnya banjir yang disebabkan oleh sampah plastik. Selain itu, lingkungan sosial yang mendukung dan banyaknya campaign tentang peduli lingkungan dan green packaging yang dilakukan berbagai pihak khususnya idola masyarakat akan mempengaruhi mereka untuk turut serta melakukan hal serupa.
Masyarakat juga sudah cukup banyak yang mengetahui Peraturan Gubernur Provinsi DKI Jakarta Nomor 142 Tahun 2019 tentang kewajiban penggunaan kantong belanja ramah lingkungan pada pusat perbelanjaan, toko swalayan dan pasar rakyat. Masyarakat berharap pemerintah akan menyiapkan strategi untuk benar-benar meniadakan kantong plastik yang ada di seluruh pusat perbelanjaan, tidak hanya di supermarket atau minimarket modern. Selain itu, upaya yang ingin dilakukan masyarakat dan diharapkan dapat dilakukan oleh semua pihak adalah dengan beralih ke green packaging sedikit demi sedikit seperti membawa kantong belanja sendiri, botol minum dan tempat makan sendiri, serta mengedukasi orang-orang disekitarnya untuk mau melakukan hal serupa.

\section{KESIMPULAN DAN SARAN}

Semakin tinggi tingkat pengetahuan akan berpengaruh baik terhadap perilaku penggunaan green packaging masyarakat DKI Jakarta. Hal tersebut disebabkan karena saat ini masyarakat masih banyak yang belum mengetahui manfaat green packaging secara benar, dan masih banyak yang lebih memilih sesuatu hal yang praktis, seperti memesan makanan 


\section{HUBUNGAN PENGETAHUAN DENGAN PERILAKU PENGGUNAAN \\ GREEN PACKAGING DI MASYARAKAT DKI JAKARTA \\ Anisa Nuraini Priambudi, Yosini Deliana}

melalui sistem delivery online yang pada akhirnya menyumbang sampah. Selain itu, masih belum terbiasanya masyarakat membawa kantong belanja sendiri ketika berbelanja dan masih ada saja yang merasa malu membuat masyarakat tersebut lebih memilih untuk membayar kantong plastik yang hanya dihargai $\mathrm{Rp}$ 200. Jika pengetahuan green packaging semakin baik maka kemungkinan akan berpengaruh baik terhadap perilaku untuk menggunakan green packaging.

Untuk meningkatkan perilaku masyarakat dalam menggunakan green packaging, pemerintah perlu memberikan sanksi yang tegas terhadap peraturan mengenai penggunaan kantong plastik. Pemerintah dapat meminta bantuan kepada kelompok-kelompok sadar lingkungan yang ada di DKI Jakarta dan memfasilitasinya untuk dapat terus mengedukasi dan melatih masyarakat untuk beralih ke green packaging.

Pemerintah juga perlu bekerjasama dengan berbagai perusahaan yang ada di DKI Jakarta untuk mewajibkan setiap karyawannya mengurangi sampah plastik minimal dengan selalu menggunakan botol minum dan tempat makan sendiri ketika di kantor atau perusahaan.

\section{DAFTAR PUSTAKA}

Arifin, M. (2017). Dampak Sampah Plastik Bagi Ekosistem Laut. Bul. Matric, 14(1), 44-48.

Asti, Surahma, dan Novita, S. (2017). Pengetahuan, sikap dan pendidikan dengan perilaku pengelolaan sampah di Kelurahan Bener Kecamatan Tegalrejo Yogyakarta. Jurnal medika respati, 12(2), 74-84.

Coniwanti, P., Laila, L., \& Alfira, M. R. (2015). Pembuatan Film Plastik Biodegredabel Dari Pati Jagung Dengan Penambahan Kitosan Dan Pemplastis Gliserol. Jurnal Teknik Kimia, 20(4).

Deliana, Y., Djuendah, E., Kusnadi, E., \& Sendjaja, T. P. (2017). The perception of green marketing (A Case in Jatinangor, West Java Province, Indonesia). International Journal of Economics Research, 14, 201-215

Deliana, Y., \& Rum, I. A. (2019). How does perception on green environment across generations affect consumer behaviour? A neural network process. International Journal of Consumer Studies, 43(4), 358-367.

Ferguson, M. J., \& Bargh, J. A. (2004). Liking is for doing: the effects of goal pursuit on automatic evaluation. Journal of personality and social psychology, 87(5), 557.

Jambeck, J. R., Geyer, R., Wilcox, C., Siegler, T. R., Perryman, M., Andrady, A., ... \& Law, K. L. (2015). Plastic waste inputs from land into the ocean. Science, 347(6223), 768771.

Kahfi, A. (2017). Tinjauan Terhadap Pengelolaan

Sampah. Jurisprudentie: Jurusan Ilmu Hukum Fakultas Syariah dan Hukum, 4(1), 12-25. 
Keman, S. (2005). Kesehatan perumahan dan lingkungan pemukiman. Jurnal Kesehatan Lingkungan Unair, 2(1).

Mahyudin, R. P. (2017). Kajian Permasalahan Pengelolaan Sampah dan Dampak Lingkungan di TPA (Tempat

Pemrosesan Akhir). Jukung (Jurnal Teknik Lingkungan), 3(1).

Muslim, E., \& Indriani, D. R. (2014). Analisis Pengaruh Eco-Label terhadap Kesadaran Konsumen untuk Membeli Green Product. Journal of Technology Management, 13(1), 86-100.

Osman, S. Jusoh, H. Amlus \& N. Khotob. (2014). Environmental Knowledge and Environmental Attitude Towards Pro-Environmental Behaviour Undergraduate Business Students Perspective. AmericanEurasian Journal of Sustainable Agriculture, 8(8), 1-4.

Ridwan, Muhamad, Achmad Fauzi D.H, dan Aniesa Samira Bafadhal. (2018). Pengaruh Green Product, Green Advertising Dan Green Brand Terhadap Keputusan Pembelian. Jurnal Administrasi Bisnis. 55(1)
Rokka, J., \& Uusitalo, L. (2008). Preference for green packaging in consumer product choices-do consumers care?. International Journal of Consumer Studies, 32(5), 516-525.

Sugiyono. (2015). Metode Penelitian Kombinasi (Mix Methods). Bandung: Alfabeta

Sumbung, H. (2012). Hubungan Antara Pengetahuan Dan Sikap Dengan Tindakan Penjual Gorengan Di Kota Manado Dalam Mengurangi Penggunaan Kantong Plastik [Skripsi]. Manado : Universitas Sam Ratulangi

Utami V, dan Prastika M.(2015). Hubungan Pengetahuan Tentang Dismenore dengan Perilaku Pencegahannya Pada Remaja Putri Kelas X dan XI di SMA Gajah Mada Bandar Lampung Tahun 2014, 1(1), 5-8 